\title{
Developing Language Skills and Building Characters through Literature
}

\author{
Fatchul Mu'in \\ Department of Language and Arts Education \\ Faculty of Teacher Training and Education \\ Universitas Lambung Mangkurat \\ Banjarmasin, Indonesia \\ Email: fatchul_muin@ulm.ac.id
}

Received:1/4/2021

Accepted: 2/10/2021

Published: 2/24/2021

\begin{abstract}
Literature is a creative and imaginative work; it records human lives or experiences using a language as its medium. Literary works as a medium rather than a goal or an end in the language instruction will be revealed. There are four language skills to be developed in the process of language instruction. These four language skills are: listening, speaking, and reading as well as writing. This paper will elaborate the aspects: (a) some reasons and strategies for a language educator to utilize the literary works in language learning and teaching, (b) benefits of the various genres of literary works towards the language teaching, (c) using literary works in the teaching of reading and writing, (d) using literary works in teaching listening and speaking, (e) advantages of learning the literary works in nation character building, and (f) suggested activities of the literary work-based teaching language skills for character building.
\end{abstract}

Keywords: character building, language skills, language instruction, literature

Cite as: Mu'in, F. (2021). Developing Language Skills and Building Characters through Literature. Arab World English Journal for Translation \& Literary Studies 5 (1) 225-233. DOI: http://dx.doi.org/10.24093/awejtls/vol5no1.16

\section{Introduction}


Literary works as a medium rather than a goal or an end in the language instruction will be revealed. It talks about human life. Literature may give us a preview of human lives or experiences; it enables us to relate to our basic levels of desire and emotion. As a product of culture, literature greatly impacts on our society's development. It has established or shaped human civilizations, and it also has changed the nation's political systems and exposed social injustice. As stated, the literature talks about human lives. The literature has to do with human activities or experiences. Some of those social activities may be peculiar, some may be more widespread, and some may be universal. Thus, we can expect that literary work records human lives or experiences. As a result of recording the human experiences, literature may register and reflect the various aspects of culture such as norms or morality, technological tools, economic system, family, political power, etc.

Literature is a creative and imaginative work; it records human lives or experiences using a language as its medium. In a narrow sense, literature can be said as a special type of language used to express human lives based on literary rules or systems. Furthermore, learning literature is meant to know literature based on literary systems. It is also meant to learn a language. Literature refers to one written by using the language. Thus, the learning of literature implies learning the language as well. Besides, as stated before, the literary work is the record of human lives or human culture. Literary works can be utilized to build our socio-cultural awareness, and in turn, they contribute to our nation's character building.

Based on the description above, literary works are the texts that can be used as materials or mediums for improving language skills (listening, speaking, reading, and writing) and at the same for building our learners' characters. Learning literature is learning a language through which our learners are made to be aware of morality.

\section{The Use of Literature in Language Teaching}

Literary work uses language as its medium. Since literary works use a language, it can be argued that a literary work is a language, that is, a language that is inherent to human values or aspects of human life. To some extent, we can say that "Literature is Language" ( Elkins, 1976, p. 2). Although literary works use language, the language in literature will be different from that beyond literature. The language in literature has its peculiarities both in form, selection, and collection. The specificity of language in literature will be different from the language used in everyday life. The use of language in literature will be different from that in the world of law. For example, a lawyer will have much to do with language, but he is not related to literature.

On the other hand, in many ways, someone involved in the literary world will relate to the use of language (Elkins, 1976, p. 3). The literary works can be used as the material for learning and teaching language skills: reading, writing, listening, speaking skills, and language 
components such as vocabulary items and grammar. The use of literary works as instructional materials is very popular within language learning and teaching. Some English language teachers have asked their students to recite poetry and the short story to train pronunciation. Some have questioned the students to improve their vocabularies through reading the literary texts, and at the same time, and develop their writing skills through reviewing the texts. Reading and reviewing the literary works allow the students to practice lexicon, syntax, semantics, pragmatics, and stylistics they have acquired through other subjects. The translation, in particular, can be stated as the implementation of the four language skills. Therefore, it is also taken into consideration in the language learning and teaching process.

In the next part, this paper will elaborate on why literary works should be used as the materials in the language classrooms. It will also determine some criteria for choosing the appropriate literary works in the English language classroom. The literary works selected should be suitable for the students' characteristics as the readers of literary works

\section{Some reasons for using literature in the classroom}

Why use literature? The use of language in literature depends on the combination of individual and social aspects of the author. The authors' creation of literary works is intended to elicit a particular response from the listener or reader. Thus, the author chooses the forms, which will generate a response from the audience or readers in his judgment. Reactions or responses will arise when the literary works are read or heard (orally performed). Therefore, literary works must be interesting to read, hear, and then discuss. The attractiveness of literary works allows language teachers, for example, to choose literary works as language teaching materials. Here are a few:

1. Literary works can be utilized as authentic material for language instruction. As original materials, the literary works present the unmodified linguistic features or components. Generally, the language in literature has specific linguistic features or components. The language of literature is more difficult to understand when compared with the ordinary language. Thus, the students' language skills from unfamiliar, unknown, or difficult language might be used outside the classroom activities.

2. Literature is useful for encouraging students in classroom interaction. The literature texts provide the readers with multiple types of meanings, and these can be explored much for the object of sharing experiences, opinions, or feeling, presentations, discussions. Semantic, pragmatic, and sociolinguistic knowledge will support these learning activities

3. Literature may extend the students' language awareness. In this relation, the students may be asked to identify the non-standardized and standardized forms of language and language varieties represented in the literary works/texts. This activity can stimulate them more aware of the socio-cultural rules in the activities in using a language. Awareness of language norms encourages people (the students) to use their language carefully and politely. Understanding this language norm is a factor that has a very big influence on actions, namely the activity of using language. 
4. Literature teaches morality. Moral in literary works usually reflects the author's life view, views on truth values, and what he wants to convey to the reader. A literary work is written by an author, among other things, to offer a model of life that he idealizes. Literary works contain moral applications in the attitudes and behavior of the characters following the views of morals. Through the characters' stories, attitudes, and behavior, readers are expected to learn from the additional messages conveyed or mandated. By examining the moral values of literary texts, teachers can encourage their students to develop attitudes (teachers). The values and attitudes adopted from literary works are related to-and beneficial to students in- the real world outside the classroom. Moral values in the literary works pertaining to good- bad, positive-negative, inappropriate, and the like may be derived from religious teachings. The principle of spiritual education is to regulate human life. Types of moral teaching can cover unlimited living problems. It can cover all the life problems, all matters relating to human dignity. The difficulties of human life can be divided into (a) human problems with themselves, (b) human relations with others in the social sphere, including with the natural environment, and (c) human relations with God. (Fatchul Mu'in, 2009)

5. Literature can increase motivation. The literary works occupy a high status of many varieties of cultures in various regions and countries. Therefore, the students may feel the meaning of great achievement in understanding literary works that are highly respected. Literary works are frequently viewed as instructional materials that are more exciting for the students than the handbooks' materials. Shortly, literary works can be something exciting and stimulating. The literature will allow its reader to imagine the world he/she is unfamiliar with. This activity is conducted by using descriptive language. For the sake of understanding, the readers may create their view or perspective about something the author is talking about. In this relation, the students will become the actors or performers in a communicative event when they are reading. Literature has become a study subject in various countries at the intermediate and tertiary levels. Still, not many language teachers have utilized literary works as the materials in the EFL/ESL classroom.

\section{Benefits of Using Literary Works in Language Teaching}

1. Literature as Authentic Material.

Authentic materials are texts produced for non-educational purposes (Bacon \& Finnemann, 1990). Since these materials are not provided for educational purposes, they are generally not taken from a given lesson book. These materials are not developed systematically in the stages for the language learners. However, many teachers or lecturers are interested in using authentic materials to learn and teach English, either written or spoken, as alternative materials. There are some kinds of authentic materials such as poetry, a short story, a novel, a song, a radio interview, a fairy story, and the like.

The authentic materials may refer to spoken or written language as the products of truthful communication and not written specifically for language teaching (Nunan, 2001). The authentic materials are regarded as media for contextualizing language learning. The authentic materials effectively present each text's context for the language learners. When the learning and teaching of English are only for studying the educational materials, the learners may solely focus more on 
the content and meaning than the context. On the other side, authentic materials will provide rich sources of context in the language instead of the language provided or presented by the teachers (Genhard, 1996).

A new pedagogical term, e.g., authentic learning, is then suggested (Herrington \& Oliver, 2000). The term authentic learning is related directly to the learners' real lives, and it prepares them to face and deal with various real-world situations. Thus, authentic learning and teaching materials and activities are planned to imitate or reflect real-world conditions Herod, 2002). When using literary works as authentic materials, the students are exposed to actual language examples from real life-like settings. In reading literary texts, students must pay attention to the target language used by native speakers of the language. The students are expected to be accustomed to the various linguistic forms, communicative functions, and meanings of the target language.

2. Language Enrichment.

Literary work provides the students with a great number of lexical or syntactic items. Words are the main elements in developing sentences. Words are formed through morphological processes, such as affixation, derivation, blending, coining, compounding, to convey the meaning stated in the sentence. Generally, lexical items can convey one meaning. Sometimes, language consists of lexical items with grammar, but not grammar that is lexicalized. All lexical items in a language are called the lexis.

The language used in literary work aims to obtain aesthetic effects obtained through creativity in expressing language, namely how an author manipulates language to express his ideas. Language in literature reflects the author's attitudes and feelings, influencing the readers' moods and emotions. Language in literary works has uniqueness, multi meanings, and multi-style. For this reason, the language in literary works must be effective and able to properly support ideas that have an aesthetic aspect in a literary work. The English language learners who read the English language well may not have difficulties understanding denotative meanings. However, they may find that sometimes the words bring around them different associations. Mastering a language could be related to a degree; knowing the meanings of all the words may not be sufficient for a full response to the work of literature. The initial step in understanding a word is to grasp its denotation. The following step is the way to understand its connotation.

Semantics is the study of meaning. Semantics examines symbols or signs that express meaning, the relationship of meaning to one another, and their influence on humans and society. Therefore, semantics includes the meanings of words, their development, and changes. The object of a semantic study is the meaning of language. More precisely, the meaning of language units such as words, phrases, clauses, sentences, and discourses. Several types of semantics, which are distinguished by level or part of the language of investigation, are the language's lexicon, so the kind of semantics is called lexical semantics. This lexical semantics is investigated by the meaning that exists in the lexemes of the language. Therefore, the meanings of those lexemes are called lexical meanings. A lexeme is a term commonly used in semantic studies to describe meaningful language units or lexical items. The term lexeme can be equivalent to a word widely used in morphological and syntactic studies, commonly defined as the smallest free grammatical unit. 


\section{Personal Involvement}

Literature can be beneficial in language instruction because of the readers' personal involvement in literary texts. The learners begin involving the literary text when they start reading the texts. They are engaged in the text. Literature can be beneficial in language instruction because of the readers' personal involvement in literary texts. The learners begin involving the literary text when they start reading the texts. They are engaged in the text. In personal involvement, the readers will become excited to pursue the development of the story. The students will be enthusiastic to know the events unfold via the climax; they feel close to particular characters and share their emotional responses. These may have beneficial effects on the process of achieving at least three language skills (reading, speaking, and writing). At this point, the literary texts chosen should have relevance with the students' needs, expectations, and interests.

\section{Some Suggested Ways of the Literary Work-Based Teaching Language Skills for Character Building.}

As authentic materials, literary works may facilitate the language learners' understanding of how communication occurs in a given country. As has been known, though literature is an imaginative one, it provides a setting based on which social and regional characteristics can be

presented. Literature provides humans' customs, feelings, thought, traditions, possessions, and their manner of speaking and behavior in various socio-cultural settings.

Literature can be seen as complementary material to the other materials provided for developing the cultural awareness of language students. Literary works, such as novels, can be viewed as portraits of human life. The author presents life models and social conditions through the novel, including social structure, social relations, social conflicts, kinship relationship, the dominance of powerful groups against the weak one, and other social aspects it happens in real life. Apart from being useful for improving language skills, literature helps make the readers aware of the sociocultural factors. Since teachers are already using literature with students, they must create their instruction more meaningful by engaging their students and promoting important moral values.

\section{The teaching of Reading and Writing}

Reading is an interactive activity to pick and understand the meaning contained in written language. Reading is also intended to obtain messages conveyed by the author through written language. Reading skills are receptive skills of written language. These can be developed from reading literary work. As a written work, literary work is more valuable than texts of non-literary work. This is because literary work has special characteristics compared to non-caste texts. The features of literary language are that: (1) it has specific forms, diction, and collection, (2) many words in it, have connotative, implied, figurative, or socio-cultural meanings, (3) it is symbolic, (3) it has multiple interpretations, and it pays attention to musical effects.

Firstly, reading literary works is intended to comprehend the denotative meaning, but it is meant to determine the connotative implication as well. Reading the literature is designed to learn what is stated in the works, either explicitly or implicitly. English language teachers should adopt the learning approach following the student-centered reading activities using literary works as the 
reading materials. In the reading course, a discussion starts from understanding denotative meaning using some questions about setting, characters, and plot, which may be responded to in specific reference to the text.

Secondly, having understood the words based on the lexical meanings, the learners might understand those found on the connotative, figurative, or implied meanings. They might create

assumptions and interpretations towards the themes of the literary work; and they might understand the points of view of the author, styles, characters, and story setting. After that, the learners should prepare themselves to conduct working together in a group discussion. The students complete the evaluations on the story and respond to the themes, point of view of the author, styles, characters, and setting of the story. This evaluation is also a suitable time for them to share their responses to the work's natural, cultural issues and themes.

Thirdly, at the evaluative level, the learners may be stimulated to think about the work and provoked to solve the problems as an effort to see their problem-solving capabilities. Group discussion started from such kind of assignment will become the starting point for either the oral or written practices. The literary work will be an essential and stimulating thing for writing in the English language, either as a model or material. When the literary work is utilized as a model, the students may imitate its topic/ theme, content, point of view, structure, and styles. When used as the material, the students make their reports showing their own thinking as their appreciation. The students may practice writing in some writing types, such as guided, free, controlled, and other writing types based on literary work.

\section{The teaching of Speaking and Listening}

Listening skill is developed through literary works. The learners are exposed to recorded or recited literary works. Using these, they will acquire how the language is spoken. They can gain knowledge of pronunciation per the sound systems of the target language. The pronunciation problem is one of the issues in learning English. The learners usually face the matter because (1) since they were children, they were wont to produce speech sounds in their own language, (2) their habits to provide speech sounds within their own language make them difficult to provide in the other language, and (3) there are different sound systems within the two languages (native and foreign languages). The learners will improve their oral production of a second or foreign language through listening activities by imitating the second or foreign language texts. This learning activity may lead to enhancing not only pronunciation but also intonation, stress, vocabulary mastery, and sentence patterns, which are, in turn, useful for developing writing and speaking competencies. Stern states that literary works in the language classroom particularly focused on reading and writing may play similarly beneficial roles in teaching either listening or speaking. Reading aloud, playing drama, improvising, role-playing, reenacting, discussing, and oral language production group activities can be based on literary works (Fatchul Mu'in et al., 2018; Nanik Mariani et al., 2019). Speaking skills will be developed through reading and paying attention to literary works like poetry and fiction prose. A lecturer may ask his student to read the texts, and at the same time, the other students hear it. Then, each student is asked to form an oral report based on what has been read or listened to. But the foremost appropriate writing is drama. The drama consists of 
dialogues. By employing a role play technique, acting is also used for developing speaking skills (Fatchul Mu'in, et l., 2018).

Literature can be used receptively and expressively in character education. Receptive use of literary works as a medium for character education is carried out in two steps:

(1)Selecting teaching materials. The literary works chosen as teaching materials are those that sound aesthetically and ethically. Those literary works should be good in literary structures and contain values that can guide students to be good human beings.

(2) Managing the learning process. In operating the learning process, the teacher must direct students in reading the literary works. Teachers must lead students to be able to find positive values from the literary works they read. Teachers should not let the students see and deduce the values existing in literary works by themselves. The teachers guide students to apply the positive values obtained from literary works in everyday life.

(3) Role-playing. The expressive use of literary works as a medium for character education can be pursued through managing emotions, feelings, enthusiasm, thoughts, ideas. Students' ideas and views are represented in creativity in writing literary works and playing drama, theater, or film. Students are guided to manage emotions, feelings, opinions, ideas, and views to be internalized within themselves and then written down into literary works. Emotions, feelings, dissatisfaction with the existing system, and anger to demonstrate towards something can be actualized in literary works, such as poetry, drama, or prose. If the students are exposed to character-rich literature in an identical manner that will serve those dual purposes, character education is often taught, encouraged, and promoted in our classrooms.

(4)The students are asked to reproduce literary works that have been read. In this case, the teacher can choose literary works that contain positive character values (poetry, short stories, dramas, or novels), then students are asked to read. After reading, students are asked to change (reproduce) into other forms of literary work. For example, short stories or novels were turned into drama; poetry was turned into short stories. In reproducing these literary works, the teacher must explain that the emphasis is on the theme. Through literary works that highlight various themes, students (humans) can be invited to recognize and understand the quality levels of their own character or character. After students acknowledge and understand the character level's quality, the teacher must guide or direct the character level's quality to a better one, namely, inviting students to "dialogue with characters in literary works that have quality levels of character at the level of" character level three. " Thus, the four types of character education models are internalized in students and actualized in daily behavior.

(5)Literary products in poetry, short stories, dramas, and novels reveal various human life themes. The themes can be grouped into receptive media for character education, simulated inside or outside the classroom (schoolyard, auditorium, or meeting room). This simulation will appeal to students in building character values. With this model, students are trained to implement character values obtained from literary works. If this simulation is often practiced, the character values

Arab World English Journal for Translation \& Literary Studies 
derived from literary works will crystallize in students' subconscious. Character values that crystallize in the subconscious can become reference values in everyday behavior.

\section{Conclusion}

First, literature plays a very important role in students' education, namely in language development, cognitive development, personality development, and social development. Second, literary works can be used receptively and expressively in character education. Third, literary works highlighting various themes that can be used as a medium for students (humans) to recognize and understand the quality of their own character levels. Fourth, literary works that describe various types of characters can be used as a medium for character education for students.

\section{About the Author:}

Fatchul Mu'in is a Lecturer in Literature/Linguistics at Universitas Lambung Mangkurat, Banjarmasin. He earned his Sarjana's degree of Linguistics from Universitas Diponegoro, Semarang (1987), Master's degree of Humanities from Universitas Gadjah Mada, Yogyakarta, and Doctoral degree from Universitas Negeri Malang, East Java, Indonesia.

ORCid ID: https://orcid.org/0000-0003-4498-3515

\section{References}

Bacon, S. M. \& Finnemann, M. D. (1990). A study of the attitudes, motives, and strategies of University foreign students. Modern Language Journal, 74 (1), 459-473.

Masny, D. (1997) Linguistic awareness and writing: Exploring the relationship with language awareness, Language Awareness, 6:2-3, 105-118, DOI: 10.1080/09658416.1997.9959921

Gerhard, J., G. (1996). Teaching English as a foreign language: A teacher self-development and methodology. Ann Arbor: the University of Michigan press.

Fatchul Mu'in. (2009). Maungkai Budaya. Banjarbaru: Scripta Cendekia.

Fatchul Mu'in, Dini Noor Arini, and Rosyi Amrina. (2018). Language in Oral Production Perspectives. Bandung : Rasibook.

Herod, L. (2002). Adult learning from theory to practice. Heinle and Heinle Publishers.

Heinemann.

Herrington, J., \& Oliver, R. (2000). "An instructional design framework for authentic learning Journal of Interactive Learning Research, 10 (1), 3-24 [8]

Tomlinson, B. (1984). A glossary of basic EFL terms. In A. Cunningsworth (Ed.), Evaluating and Selecting EFL Teaching Materials (pp. 80-102). London: Heinemann.

Nanik Mariani, Fatchul Mu'in \& Yusuf Al Arief. (2019). Introduction to Linguistics. Banjarmasin: Jurusan PBS FKIP Universitas Lambung Mangkurat.

Nunan, D. (2001). Second language teaching and learning. Boston: Heinle and Heinle Publishers. 